\title{
The early care environment and DNA methylome variation in childhood
}

\author{
ELIKA GARG, ${ }^{a}$ LI CHEN,${ }^{b}$ THAO T. T. NGUYEN, ${ }^{a}$ IRINA POKHVISNEVA, ${ }^{a}$ LAWRENCE M. CHEN,${ }^{a}$ \\ EVA UNTERNAEHRER,${ }^{a, c}$ JULIA L. MACISAAC, ${ }^{d}$ LISA M. MCEWEN,${ }^{d}$ SARAH M. MAH ${ }^{d}$ \\ HELENE GAUDREAU, ${ }^{a}$ ROBERT LEVITAN,${ }^{e, f}$ ELLEN MOSS, ${ }^{g}$ MARLA B. SOKOLOWSKI,${ }^{e, h}$ \\ JAMES L. KENNEDY, ${ }^{e f f}$ MEIR S. STEINER, ${ }^{i}$ MICHAEL J. MEANEY, ${ }^{a, b, h}$ JOANNA D. HOLBROOK, ${ }^{b j, j}$ \\ PATRICIA P. SILVEIRA,${ }^{a}$ NEERJA KARNANI, ${ }^{b}$ MICHAEL S. KOBOR,${ }^{d, h}$ KIERAN J. O'DONNELL,${ }^{a, h}$ AND \\ MAVAN STUDY TEAM \\ ${ }^{a}$ McGill University; ${ }^{b}$ Agency for Science Technology and Research $(A * S T A R)$, Singapore; ${ }^{c}$ University of Konstanz, Germany; \\ ${ }^{d}$ University of British Columbia; ${ }^{e}$ University of Toronto; ${ }^{f}$ Centre for Addiction and Mental Health, Toronto; ${ }^{g}$ University of Quebec at \\ Montreal; ${ }^{h}$ Canadian Institute for Advanced Research, Toronto; ${ }^{i}$ McMaster University; ${ }^{j}$ National University of Singapore; and \\ ${ }^{k}$ University of Southampton
}

\begin{abstract}
Prenatal adversity shapes child neurodevelopment and risk for later mental health problems. The quality of the early care environment can buffer some of the negative effects of prenatal adversity on child development. Retrospective studies, in adult samples, highlight epigenetic modifications as sentinel markers of the quality of the early care environment; however, comparable data from pediatric cohorts are lacking. Participants were drawn from the Maternal Adversity Vulnerability and Neurodevelopment (MAVAN) study, a longitudinal cohort with measures of infant attachment, infant development, and child mental health. Children provided buccal epithelial samples (mean age $=6.99, S D=1.33$ years, $n=226$ ), which were used for analyses of genome-wide DNA methylation and genetic variation. We used a series of linear models to describe the association between infant attachment and (a) measures of child outcome and (b) DNA methylation across the genome. Paired genetic data was used to determine the genetic contribution to DNA methylation at attachment-associated sites. Infant attachment style was associated with infant cognitive development (Mental Development Index) and behavior (Behavior Rating Scale) assessed with the Bayley Scales of Infant Development at 36 months. Infant attachment style moderated the effects of prenatal adversity on Behavior Rating Scale scores at 36 months. Infant attachment was also significantly associated with a principal component that accounted for $11.9 \%$ of the variation in genome-wide DNA methylation. These effects were most apparent when comparing children with a secure versus a disorganized attachment style and most pronounced in females. The availability of paired genetic data revealed that DNA methylation at approximately half of all infant attachment-associated sites was best explained by considering both infant attachment and child genetic variation. This study provides further evidence that infant attachment can buffer some of the negative effects of early adversity on measures of infant behavior. We also highlight the interplay between infant attachment and child genotype in shaping variation in DNA methylation. Such findings provide preliminary evidence for a molecular signature of infant attachment and may help inform attachment-focused early intervention programs.
\end{abstract}

Studies of maternal mental health (O'Donnell, Glover, Barker, \& O'Connor, 2014; O'Donnell \& Meaney, 2016; Pawlby, Hay, Sharp, Waters, \& O'Keane, 2009), institutional rearing (McLaughlin et al., 2014; Nelson et al., 2007; Rutter, Kumsta, Schlotz, \& Sonuga-Barke, 2012; Sonuga-Barke et al., 2017), and childhood abuse (Klengel et al., 2013; Nanni, Uher, \& Danese, 2012; Spatz Widom, DuMont, \& Czaja, 2007) reflect

We are grateful to the participants and to Katherine O'Donnell, Tie Yuan Zhang, and Josie Diorio for helpful discussions. This work was funded by a grant from Brain Canada (Canadian Neuroepigenetics Network), the Ludmer Centre for Neuroinformatics and Mental Health, and the Sackler Program for Epigenetics and Psychobiology. Kieran J. O'Donnell is an Azrieli Canadian Institute For Advanced Research (CIFAR) Global Scholar. Michael J. Meaney, Michael S Kobor, and Marla Sokolowski are Fellows of the CIFAR Child and Brain Development Program.

Address correspondence and reprint requests to: Kieran J. O'Donnell, the Ludmer Centre for Neuroinformatics and Mental Health, Douglas Mental Health University Institute, McGill University, 6875 Lasalle Boulevard, Montreal, Quebec, Canada H4H 1R3; E-mail: kieran.odonnell@mcgill.ca. the profound influence of the early environment on child development and later mental health. However, not all children are affected equally, with a subset of children seemingly resilient to some of the negative consequences of early life adversity. Early intervention programs that seek to mitigate the negative sequelae associated with early life adversity would benefit from a better understanding of such resilience.

The genome is one source of individual differences in sensitivity to the early environment. The negative effects of maternal antenatal anxiety on child emotional problems (O'Donnell, Glover, Holbrook, \& O'Connor, 2014), working memory, and symptoms of ADHD (O'Donnell et al., 2017) are moderated, in part, by genetic variation in the child. Likewise, polygenic variation across the serotonin and dopamine signaling pathways moderates the impact of prenatal adversity (Silveira et al., 2017) and early caregiving (Belsky \& van IJzendoorn, 2017; Stocker et al., 2017) on child neurodevelopment and long-term mental health outcomes. 
The quality of the early caregiving environment can also contribute to individual differences in susceptibility to the negative effects of early adversity. Bergman, Sarkar, Glover, and O'Connor (2010) highlight infant attachment security as a moderator of prenatal adversity effects on infant cognitive development. In their study of women undergoing amniocentesis, the authors report an inverse association between fetal cortisol exposure and measures of cognitive development at 17 months. This relationship was only evident in infants with an insecure attachment style. Likewise, McGoron et al. (2012) report that infant attachment security limited the impact of institutional rearing on measures of child psychopathology. Taken together, these findings suggest the early caregiving environment can buffer some of the negative consequences of adversity experienced in the prenatal and early postnatal environment. The biological basis of such effects is not well understood.

Chemically stable, epigenetic modifications, such as DNA methylation, have emerged as a putative mechanism for the enduring effects of the early environment on neural development and function (Meaney \& Ferguson-Smith, 2010). DNA methylation can modulate gene expression as well as splicing events (Maunakea, Chepelev, Cui, \& Zhao, 2013; Maunakea et al., 2010), thus creating a diversity of transcriptional programs from a single genome. The human DNA methylome is dynamic across development (Teh et al., 2014; Ziller et al., 2013) and is altered by early social experience (Klengel et al., 2013; Lam et al., 2012; O'Donnell et al., 2018). Studies using rodent models reveal effects of parent-offspring interactions on the methylation status of a range of genes implicated in hypothalamic-pituitary-adrenal stress responses as well as synaptic function (Bagot et al., 2012; Klengel et al., 2013; Lam et al., 2012; Murgatroyd et al., 2009; O'Donnell et al., 2018; Roth, Lubin, Funk, \& Sweatt, 2009; Weaver et al., 2004; Wu, Patchev, Daniel, Almeida, \& Spengler, 2014; Zhang et al., 2010).

Genome-wide analyses of DNA methylation in humans reveal broad effects of childhood abuse (Mehta et al., 2013; O'Donnell et al., 2018; Suderman et al., 2012). However, few studies examine whether variations in parent-offspring interactions lying within the normal range are a source of variation in the DNA methylome. One recent study reports an association between one specific component of caregiving, the amount of physical contact between mothers and their infants, and variation in DNA methylation (Moore et al., 2017). However, Moore et al. did not examine how the quality of such mother-infant interactions predicted variation in the DNA methylome.

Infant attachment is an objective measure of the early care environment that associates with child mental health outcomes (Fearon, Bakermans-Kranenburg, van IJzendoorn, Lapsley, \& Roisman, 2010; Groh et al., 2014; Groh, Roisman, van IJzendoorn, Bakermans-Kranenburg, \& Fearon, 2012) and may buffer the effects of prenatal adversity on measures of child development (Bergman et al., 2010; McGoron et al., 2012). In this study we use a prospective, longitudinal cohort of typically developing children to describe the association between infant attachment and variation in DNA methylation across the genome.

\section{Method and Materials}

\section{Participants}

Participants $(N=226: 111$ female, 115 male, mean age $=$ $6.99, S D=1.33$ years) were drawn from the Maternal Adversity, Vulnerability and Neurodevelopment (MAVAN) cohort (O’Donnell, Gaudreau, et al., 2014). Full ethical approval for this study was provided by the institutional review boards at the Douglas Research Institute and McMaster University.

\section{The early care environment}

Infant attachment was assessed at 36 months using a modified version of the Strange Situation (Moss, Bureau, Cyr, Mongeau, \& St.-Laurent, 2004). This 20-min observational assessment consists of a sequence of separations/reunions lasting 5 min each: (1) separation between mother and child; (2) reunion; (3) second separation; and (4) second reunion. Behavior was coded during each reunion episode giving rise to one of four attachment classifications: secure, avoidant, ambivalent, or disorganized (Moss, Cyr, Bureau, Tarabulsy, $\&$ Dubois-Comtois, 2005). A secure attachment style is characterized by increased exploration in the presence of the primary caregiver and generally associates with more favorable developmental outcomes. Insecure attachment is characterized by reduced exploration, even in the presence of the primary caregiver. Insecurely attached infants are further subdivided as either "avoidant" of the primary caregiver during stress or striving to maintain close proximity to the primary caregiver, but not soothed during distress (ambivalent). Disorganized attachment describes infants who fail to show an "organized" strategy for eliciting the attention of the primary caregiver during stress, who display stress-associated behaviors (e.g., hunched shoulders or freezing) and may show evidence of role-reversed behavior (e.g., attempting to control the caregiver; Moss et al., 2005). Disorganized attachment is also associated with an increased risk of later psychopathology (Fearon et al., 2010; Groh et al., 2012; Scholtens, Rydell, Bohlin, \& Thorell, 2014). Trained observers scored all videos and demonstrated excellent interrater reliability $(\kappa=0.83)$. Due to the small number of avoidant $(n=13)$ and ambivalent $(n=25)$ cases, both groups were combined to form an organized-insecure category.

\section{Biological sample collection}

We collected buccal epithelial cells (Catch-All Swabs, Epicentre, USA) from all children (mean age $=6.99, S D=$ 1.33 years). Buccal cell collection is minimally invasive, provides a relatively homogenous cell type (squamous epithelium) for DNA methylation analyses (Berko et al., 2014; 
Lowe et al., 2013), and may serve as an appropriate surrogate for neural tissue given their shared ectodermal lineage. Papavassiliou et al. (2009) report that trisomy mosaicism in buccal cells is a stronger predictor of cognitive impairment in Down syndrome patients than mosaicism determined in lymphocytes (Papavassiliou et al., 2009). Likewise, Smith et al. (2015) report greater similarity between DNA methylome profiles derived from neural tissue and saliva than bloodbased data. Smith et al. suggest that this brain-saliva similarity is driven, in part, by the proportion of epithelial cells within saliva samples.

\section{DNA methylation analyses}

Genomic DNA was extracted using the Masterpure system (Epicentre, USA) and quantified using a NanoPhotometer P300 (Implen, Germany). The genomic DNA (750 ng) was bisulfite converted using the EZ-DNA Methylation Kit (Zymo Research, USA) and isothermally amplified at $37{ }^{\circ} \mathrm{C}$ for $22 \mathrm{hr}$, enzymatically fragmented, purified, and hybridized on Infinium HumanMethylation 450 beadchip array $(450 \mathrm{~K}$, Illumina). The $450 \mathrm{~K}$ array permits quantification of DNA methylation with single-base resolution across multiple probes, including 482,421 $\mathrm{CpG}$ sites and 3,091 non-CpG sites (Bibikova et al., 2011). Our studies with this technology suggest strong reproducibility and good correlation with bisulfite sequencing, including reduced representational bisulfite sequencing and confirmatory pyrosequencing (Marr et al., 2014; O’Donnell et al., 2018; Pan et al., 2012). The $450 \mathrm{~K}$ chips were scanned using the Illumina HiScan system and the image data were processed in $\mathrm{R}$ ( $\mathrm{R}$ Core Team, 2014) using the Minfi package (Aryee et al., 2014).

The experiment was run in 4 batches together with a series of internal controls distributed across each batch and longitudinal samples (Forest et al., 2018). We report findings from DNA methylation data generated from the first biological sample collection, which children provided at age 6.99 years $(S D=1.33)$.

$450 K$ data processing. DNA methylation data were processed in $\mathrm{R}$ using the Minfi package (Aryee et al., 2014). Samples that failed standard Minfi quality control (QC; QC threshold $=10.5$ ) were removed (Aryee et al., 2014). All remaining samples had a high call rate $(>95 \%)$. Probes with a low call rate $(<75 \%)$, a high detection $p$ value $(p>.05$; Lehne et al., 2015), and a low number of beads (less than 3 in $>5 \%$ of the cohort) were also removed. Predicted sex (from DNA methylation of the sex chromosomes; Aryee et al., 2014) and reported sex for all participants was consistent for all samples. Nonspecific probes or probes with single nucleotide polymorphism (SNP)-disrupting polymorphisms were removed (Chen et al., 2013; Price et al., 2013), along with all the probes on the sex chromosomes. Unwanted technical variation was accounted for, in part, using functional normalization based on principal component analysis of control probes on the $450 \mathrm{~K}$ (Fortin et al., 2014). We also used
ComBat (Johnson, Li, \& Rabinovic, 2007) to iteratively adjust our data for unwanted technical variation associated with experimental batch, array row (sentrix row), and plate position (sample column). Hierarchical clustering showed that technical replicates were more closely related to each other than to other individuals. Therefore, replicates from the same individual were combined such that each participant contributed one unique data point in our analyses. The data set was further reduced to probes showing interindividual variation, defined as probes with a range of methylation ( $\beta$ value $\geq 0.10$ ) corresponding to at least a $10 \%$ difference in DNA methylation across participants. A total of 252,439 probes remained and were denoted as variably methylated probes (VMPs).

Cell type adjustments. We used the method described by Smith et al. (2015) to predict buccal epithelial cell content of each sample. The proportion of buccal cells per sample was added as a covariate to all models describing variation in DNA methylation.

\section{Genetic analyses}

We used the PsychChip and the commercially available PsychArray (Illumina) to describe genetic variation within this cohort. Only shared SNPs (between the PsychChip and the PsychArray) were considered. SNPs with a low call rate (i.e., called in $<95 \%$ of samples) and samples with a low call rate (i.e., $<95 \%$ of SNPs called within a sample) were removed, resulting in 223 participants and 228,562 autosomal SNPs. Next, we used the Sanger Imputation Service to impute missing genotypes, resulting in $\sim 17 \mathrm{M}$ SNPs per participant.

Population structure. We filtered the genetic data set to retain SNPs in low linkage disequilibrium $\left(r^{2}<.25\right)$. These SNPs were then subjected to principal component analysis (PCA) in EIGENSTRAT, an established method to describe population structure (Price et al., 2006). Two principal component scores were included in all analyses to account for population stratification/ancestry effects.

Child outcome measures. We used the Bayley Scales of Infant Development II (BSID) to assess child motor development (Psychomotor Development Index; PDI) and mental development (Mental Development Index; MDI) at 36 months (Bayley, 1993). We also rated child behavior (Behavior Rating Scale; BRS) during the BSID across multiple domains (e.g., attention/arousal, orientation/engagement, emotional regulation, and motor quality) to index child performance during this mildly stressful, novel task.

Mothers completed a series of questionnaires concurrent with buccal sample collection from their children (see Table 1 for maternal and child age at time of collection). We used the maternal report from the Strengths and Difficulties Questionnaire (SDQ; Goodman, Meltzer, \& Bailey, 1998) to describe 
Table 1. MAVAN 450K cohort characteristics

\begin{tabular}{|c|c|}
\hline MAVAN 450K Cohort & $N=226$ \\
\hline Age $(S D)$ & $6.99(1.33)$ \\
\hline \multicolumn{2}{|l|}{ Biological sex } \\
\hline Female $(\%)$ & $111(49.1)$ \\
\hline Infant attachment at 36 months $(\%)$ & 195 \\
\hline Secure & $110(48.7)$ \\
\hline Insecure ${ }^{\dagger}$ & $38(16.8)$ \\
\hline Disorganized & $47(20.8)$ \\
\hline Missing & $31(13.7)$ \\
\hline \multicolumn{2}{|l|}{ BSID at 36 months } \\
\hline Behavior Rating Scale $(S D)$ & $122.85(6.43)$ \\
\hline Missing (\%) & $13(5.8)$ \\
\hline Mental Development Index $(S D)$ & $98.72(10.86)$ \\
\hline Missing (\%) & $17(7.5)$ \\
\hline Psychomotor Development Index (SD) & $101.15(12.86)$ \\
\hline Missing (\%) & $15(6.6)$ \\
\hline \multicolumn{2}{|l|}{ SDQ at time of biosample collection } \\
\hline Total SDQ Score $(S D)$ & $8.29(4.94)$ \\
\hline Missing (\%) & $4(1.8)$ \\
\hline \multicolumn{2}{|l|}{ Genetic variation/SNP data } \\
\hline Available $(\%)$ & $223(98.7)$ \\
\hline Prenatal Adversity Score (\%) & 180 \\
\hline 0 & $63(27.9)$ \\
\hline 1 & $48(21.2)$ \\
\hline 2 & $46(20.4)$ \\
\hline 3 & $10(4.4)$ \\
\hline 4 & $9(4.0)$ \\
\hline$\geq 5$ & $4(1.7)$ \\
\hline Missing & $46(20.4)$ \\
\hline \multicolumn{2}{|l|}{ Maternal age $(S D)$} \\
\hline At birth of study child & $30.53(4.95)$ \\
\hline $\begin{array}{l}\text { At time of recruitment/ } \\
\text { data collection for } 450 \mathrm{~K} \text { cohort }\end{array}$ & $37.58(4.89)$ \\
\hline \multicolumn{2}{|l|}{ Maternal education } \\
\hline University educated (\% Yes) & $119(52.7)$ \\
\hline \multicolumn{2}{|l|}{ Maternal anxiety } \\
\hline STAI $(S D)$ & $35.55(11.04)$ \\
\hline Missing (\%) & $5(2.2)$ \\
\hline
\end{tabular}

Note: BSID, Bayley Scales of Infant Development. SDQ, Strengths and Difficulties Questionnaire. STAI, Spielberger Trait Anxiety Inventory. ${ }^{\dagger}$ Avoidant $(n=13)$ and ambivalent $(n=25)$ attachment classifications were combined to form an "organized" insecure group.

symptoms of child emotional/behavioral problems. This well-validated screening assessment provides symptom data on four domains related to emotional difficulties, inattention/hyperactivity, conduct problems, and peer relations. A summary score of these four problem subscales contributes to the total SDQ score, which shows good predictive validity for child mental health problems (Goodman, Ford, Simmons, Gatward, \& Meltzer, 2000; Goodman, Renfrew, \& Mullick, 2000). Mothers also completed the Spielberger State/Trait Anxiety Inventory (Spielberger, Gorusch, \& Lushene, 1970), which we used to index maternal trait anxiety at the time of biological sample collection from their child. Finally, maternal education (university educated or not) was coded as a binary variable and considered in all analyses.
Data analysis

Variably methylated probes (VMPs; $n=252,439$ ) were subjected to PCA in R. We focus our analysis on the first 10 principal components (PCs) that account for $41.9 \%$ of the variance in our DNA methylation data (Figure 1). We used one-way analysis of variance (ANOVA) models to describe associations between infant attachment and PCs scores. ANOVA models were adjusted for measures of cellular heterogeneity in buccal samples, child biological sex and age, measures of population stratification derived from genetic data, and maternal anxiety and level of education. Attachment style was coded as a categorical nonordinal measure.

The following linear regression model was tested to identify VMPs for which methylation levels were predicted by attachment:

$$
\begin{aligned}
& \text { Model } 1(E \text { Model }): V M P \sim \text { attachment }+ \text { age }+ \\
& \text { sex }+ \text { pop. strat. }+ \text { BCC }+ \text { mat. anx. }+ \text { mat. edu },
\end{aligned}
$$

where VMP represents \%methylation at a single variably methylated probe; attachment is attachment style, coded into three groups: secure, insecure, and disorganized with secure as the reference category; sex is biological sex of participant, age is age in days at time of buccal sample collection; pop. strat. represents principal components one and two from a PCA of genetic data; BCC is buccal cell composition expressed as a percentage; mat. anx. represents maternal Spielberger State/Trait Anxiety Inventory score at time of biosample collection; and mat. educ. is maternal level of education as a proxy for socioeconomic status.

VMPs that were associated with infant attachment $(p<$ $.05)$ were mapped to genes using Illumina annotation and entered into a Genego Metacore analysis to identify enrichment of biological pathways and processes within our methylation data set. We used MetaCore + MetaDrug version 6.18 (Thomson Reuters, USA).

Genetic contribution to DNA methylation at attachment-associated VMPs. We sought to determine if genetic variation in cis (within 10 kilobases; $10 \mathrm{~kb}$ ) contributed to variation in DNA methylation at attachment-associated VMPs. We tested for main effects of all SNPs in cis adjusting for relevant covariates (see Model 2). One SNP was tested per model and adjusted for relevant covariates:

$$
\begin{aligned}
& \text { Model } 2(G+E \text { Model }): V M P \sim \text { attachment }+ \\
& S N P_{i . . . j}+\text { age }+ \text { sex }+ \text { pop. strat } .+B C C+ \\
& \text { mat. anx. }+ \text { mat. edu },
\end{aligned}
$$

where $\mathrm{SNP}_{i \ldots j}$ represents the first to the last SNP within a 10$\mathrm{kb}$ window from the attachment-associated VMP.

In parallel, we ran a series of linear models that included an interaction term between infant attachment and each SNP in cis to predict DNA methylation at attachment-associated 


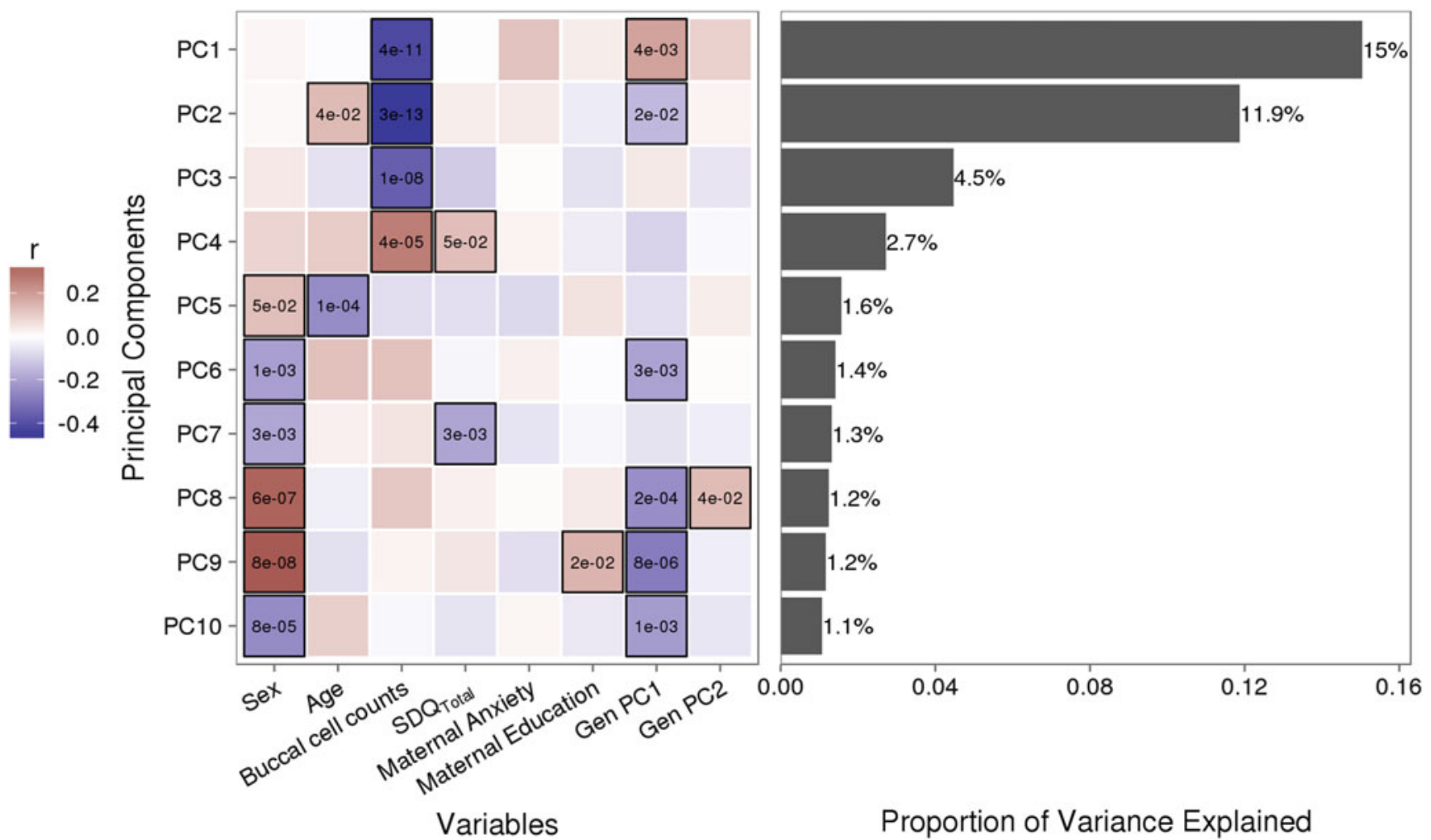

Figure 1. Sources of variation in the DNA methylome. (a) Heatmap describes the bivariate association between variables of interest and the first 10 principal components (PCs) from a principal component analysis of variably methylated probes. The $p$ values are provided for significant associations $(p<.05)$. (b) Bars describe the proportion of variance explained by each principal component. SDQ ${ }_{\text {Total }}$, Strengths and Difficulties Questionnaire total scale score. GenPC1/GenPC2, first and second principal component score from principal component analysis of genetic variation.

VMPs (Model 3). One SNP and its corresponding interaction term with infant attachment was tested per model and adjusted for relevant covariates:

$$
\begin{gathered}
\text { Model } 3(G \times E \text { Model }): V M P \sim \text { attachment }+ \\
S N P_{i \ldots .}+\text { attachment }{ }^{*} S N P_{i . . j}+\text { age }+ \text { sex }+ \\
\text { pop. strat. }+ \text { BCC }+ \text { mat. anx. }+ \text { mat. edu },
\end{gathered}
$$

where attachment ${ }^{*} S N P_{i \ldots .}$ is the interaction term between infant attachment and the first to the last SNP within a 10-kb window from the attachment-associated VMP.

We ranked these additive $(G+E)$ models per VMP to identify the SNP in cis that accounted for the largest proportion of variance in DNA methylation (i.e., highest model adjusted $R^{2}$ ) at a given VMP. Next, we ranked all interaction ( $\mathrm{G} \times \mathrm{E}$ ) models per VMP to identify the SNP, which in interaction with infant attachment, accounted for the largest proportion of variance in DNA methylation at a given VMP (i.e., highest model adjusted $R^{2}$ ). We selected VMPs for which the top ranked SNP from the additive and interaction model was the same, permitting a direct comparison of models (i.e., a comparison of nested models; Belsky, Pluess, \& Widaman, 2013). We compared adjusted $R^{2}$ across each of these three models to identify the model that best explained DNA methylation at attachment-associated VMPs (i.e., the model with the highest adjusted $R^{2}$ ). We also compared our results based on percentage variance explained (adjusted $R^{2}$ ) to a parallel analysis using the Akaike information criterion (AIC), which permits the comparison of nonnested models.

\section{Supplementary analyses}

The MAVAN study collected data on a number of measures related to the prenatal period. We used these data to determine if infant attachment buffers the negative effects of prenatal adversity on infant (BSID) and child (SDQ) outcomes, in line with previous reports for different cohort studies (Bergman et al., 2010; McGoron et al., 2012).

Prenatal adversity. We used a cumulative measure of prenatal adversity described and validated previously within the MAVAN cohort (Silveira et al., 2017). Information on maternal antenatal illness, birth size, gestational age, household income, lack of material resources, domestic violence, marital strain, maternal anxiety, and maternal depression was combined to form a cumulative score that ranged from 0 to 9. Data on prenatal adversity were available on $n=180$ participants included in the subsample of the MAVAN cohort (see Table 1). We used linear regression analysis to test the association between prenatal adversity and (a) infant BSID and 


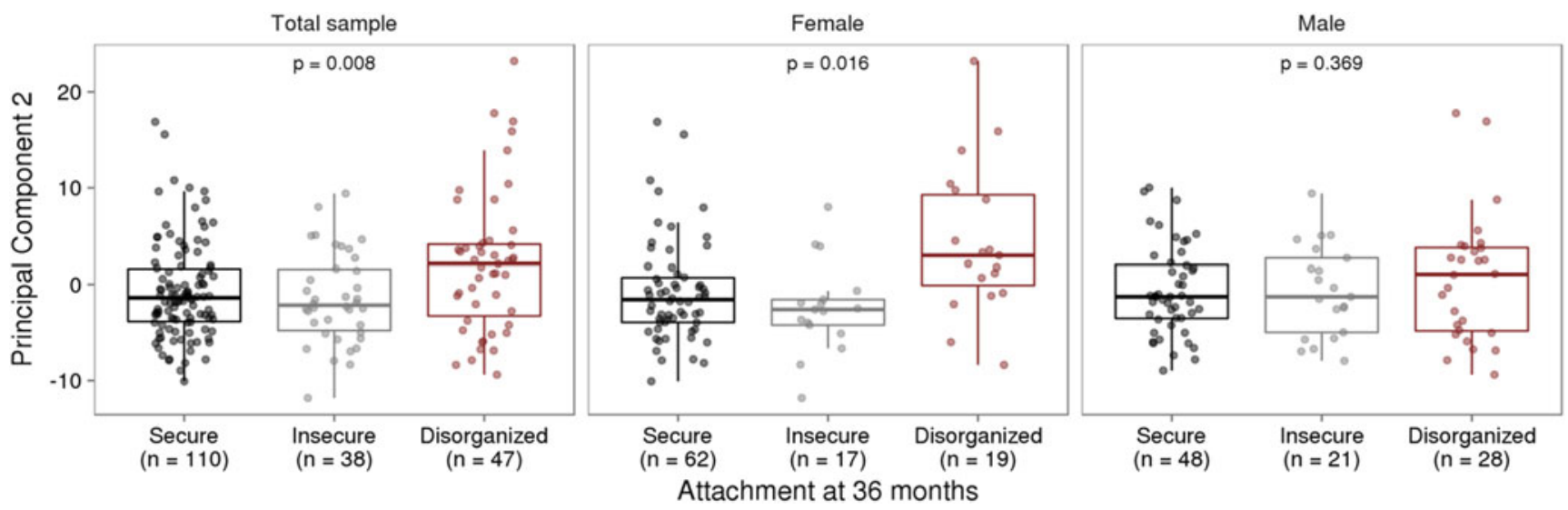

Figure 2. Infant attachment and variation in DNA methylation. (a) Infant attachment associates with principal component two (PC2). PC2 accounts for $11.9 \%$ of the variance in DNA methylation of variably methylated probes. (b) Sex-stratified analyses show these effects are evident in females but not in males. The $p$ values are derived from analysis of variance.

(b) child SDQ scores. We also included interaction terms between prenatal adversity and infant attachment classification.

Biological sex-specific effects. We also carried out a series of analyses stratified by biological sex to examine differences in the association between infant attachment and variation in DNA methylation between males and females.

\section{Results}

Table 1 describes the characteristics of the children and mothers included in our analysis. There were no significant differences in the age $(p=.081)$ or biological sex $(p=.198)$ of participants across the different attachment classifications.

\section{Infant attachment and child outcomes}

One-way ANOVA models showed a significant association between infant attachment and the Mental Development Index, MDI: $F(2,189)=13.864, p<.001$, Cohen's $f=.39$, and Behavior Rating Scale, BRS: $F(2,192)=10.74, p<.001$, Cohen's $f=0.34$, from the BSID at 36 months. Infant attachment was associated with infant psychomotor development (PDI) at trend level, $F(2,190)=2.385, p=.095$, Cohen's $f=0.16$. Posthoc analyses of these significant associations revealed differences between the secure and disorganized groups on BRS and MDI scores with large effect sizes (Cohen's $d \geq 0.84$ ), and between the insecure and disorganized groups with medium effect size (Cohen's $d \geq 0.46$; BRS: all adjusted $p \leq .026$; MDI: all adjusted $p \leq .001$ ). No significant differences were observed between infants with a secure and those with an insecure attachment classification for MDI or BRS scores. These results were largely unchanged following adjustment for child biological sex, population stratification, and maternal education, MDI: $F(2,187)=12.425$, $p<.001$; BRS: $F(2,190)=8.679, p<.001$; PDI: $p>.1$.

One-way ANOVA models showed a significant association between infant attachment and child mental health, total
SDQ: $F(2,192)=3.389, p=.036$, Cohen's $f=0.19)$. Post hoc tests revealed significant differences between the secure and disorganized groups (adjusted $p=.033$ ) with a medium effect size (Cohen's $d=0.45$ ), with no difference between secure and insecure groups. This association was somewhat reduced following adjustment for child age, biological sex, population stratification, and maternal education, total SDQ: $F(2,190)=2.654, p=.073$. However, when we considered maternal anxiety at the time of SDQ report, to control for potential reporter bias, infant attachment was no longer associated with child total SDQ score $(p=.513)$.

\section{Infant attachment and variation in DNA methylation: Principal components analysis}

Figure 1 illustrates the bivariate associations between predictors of interest and the first $10 \mathrm{PC}$ scores from a PCA of VMPs.

Infant attachment was significantly associated with $\mathrm{PC} 2, F$ $(2,189)=4.964, p=.008$, Cohen's $f=0.24$, after adjustment for child age, biological sex, cellular heterogeneity within buccal samples, population stratification, and measures of maternal education and anxiety at time of biosample collection (Figure 2).

\section{Infant attachment and variation in DNA methylation: VMP analysis}

No individual VMP passed a Benjamini-Hochberg false discovery rate correction. However, the $p$ value distribution for the model was substantially skewed (Figure 3). A large number of VMPs were associated with infant attachment at a nominal level (unadjusted $p=.05$ ). This skewed $p$ value distribution differs from the uniform flat distribution expected under the null hypothesis (i.e., no association between DNA methylation and infant attachment). These differences were most striking for comparisons between secure and disorganized groups $(n=35,761$, unadjusted $p<.05)$. 


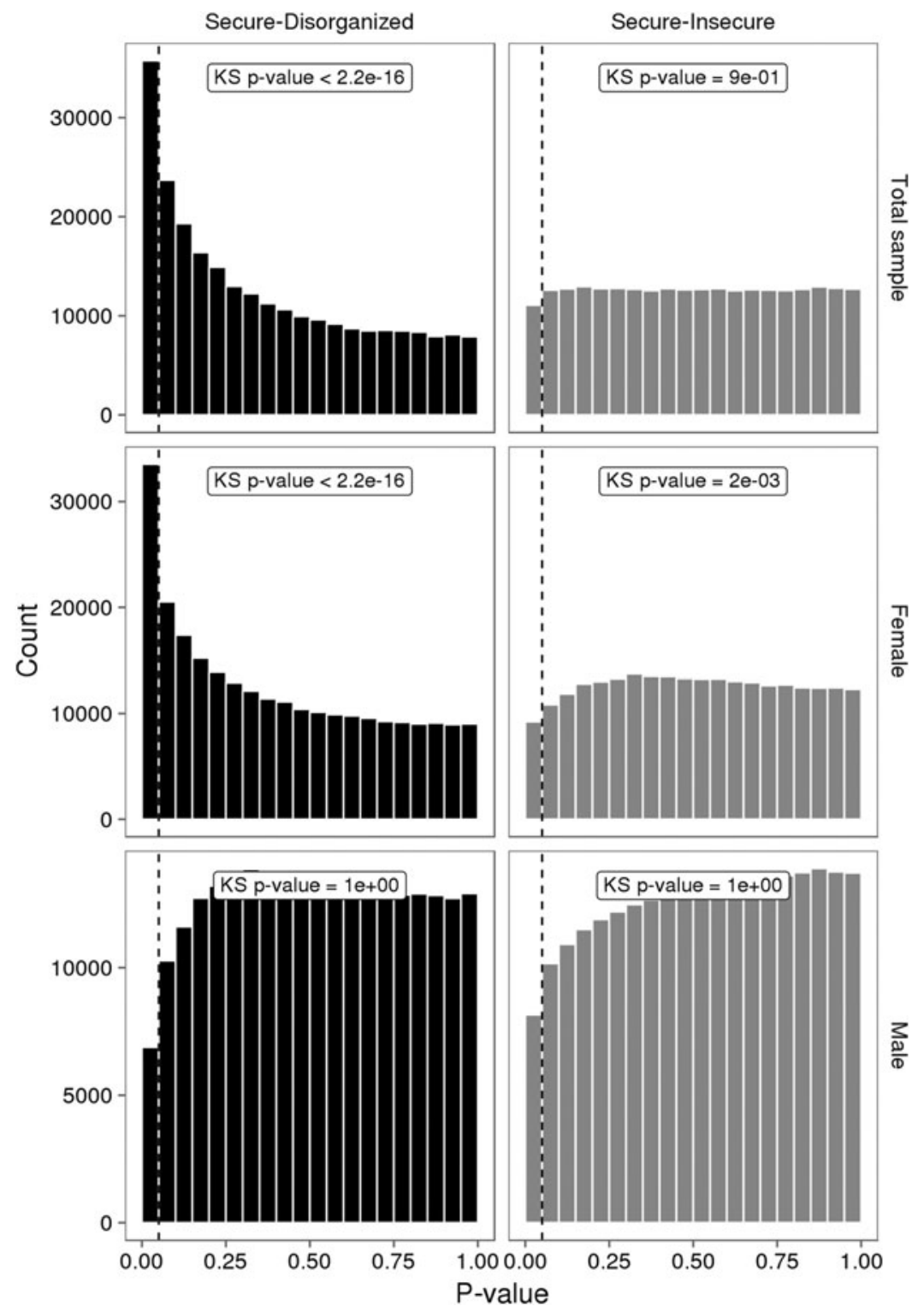

Figure 3. The $p$ value distributions for linear models describing the association between infant attachment and variably methylated probes. The $p$ values derived from one-tailed Kolmogorov-Smirnov (KS) test for uniformity of distribution.

Of note, attachment-associated VMPs (secure vs. disorganized $n=35,761$, nominal $p<.05$ ) were located in genes for which gene expression has been shown to covary with individual differences in early life experience (Anacker et al., 2013; Klengel et al., 2013; Pena, Neugut, \& Champagne, 2013; Wu et al., 2014). These included multiple VMPs within the glucocorticoid receptor (NR3C1; $\operatorname{cg} 08845721, \operatorname{cg} 13648501$, cg16586394, cg19457823, cg20753294), estrogen receptor-alpha $(E S R 1 ; \operatorname{cg} 07455133, \operatorname{cg} 07746998, \operatorname{cg} 08907436$, cg17264271, cg25490334), as well as genes involved in glucocorticoid signaling (SGK1: cg06849960, cg09872934, cg11856561 cg12871835 SGK2: cg21685427, FKBP5: cg07061368, cg07843056 and POMC: cg11894631; see online-only Supplemental Table S.1 for all attachmentassociated VMPs).
Pathway analysis of attachment-associated VMPs (nominal $p<.05$ ) showed significant enrichment for multiple pathways associated with cell signaling and cell adhesion (Table 2), including the Ephrin signaling pathway.

\section{Child genetic variation contributes to DNA methylation at attachment-associated VMPs}

We focused our genetic analysis on attachment-associated VMPs identified from our comparison of secure versus disorganized groups (see Model 1) with at least one SNP in cis $(n=30,965)$. We identified the SNP from the additive $(\mathrm{G}+\mathrm{E}$ model; Model 2) or interaction (G x E model; Model 3$)$ models that accounted for the largest proportion of variance in DNA methylation at a specific VMP (see Methods). 
Table 2. Pathway and process enrichment analysis of attachment-associated variably methylated probes

\begin{tabular}{llcc}
\hline \hline Rank & Biological pathways & $p$ value & FDR \\
\hline 1 & Ephrin signaling & $2.57 \mathrm{E}-05$ & $2.45 \mathrm{E}-02$ \\
2 & POMC processing & $5.91 \mathrm{E}-05$ & $2.68 \mathrm{E}-02$ \\
3 & VEGF signaling via VEGFR2 & $8.46 \mathrm{E}-05$ & $2.68 \mathrm{E}-02$ \\
4 & Receptor-mediated axon growth repulsion & $1.20 \mathrm{E}-04$ & $2.86 \mathrm{E}-02$ \\
5 & SDF-1 signaling in hematopoietic stem cells & $3.51 \mathrm{E}-04$ & $4.81 \mathrm{E}-02$ \\
\hline & Biological processes & \\
& & \\
1 & Cell adhesion: Attractive and repulsive receptors & $1.58 \mathrm{E}-05$ & \\
2 & Cell adhesion: Cell junctions & $2.14 \mathrm{E}-05$ & $1.48 \mathrm{E}-03$ \\
3 & Potassium transport & $2.79 \mathrm{E}-05$ & $1.48 \mathrm{E}-03$ \\
4 & Cell adhesion: Platelet aggregation & $4.10 \mathrm{E}-05$ & $1.63 \mathrm{E}-03$ \\
5 & Neurogenesis: Axonal guidance & $7.38 \mathrm{E}-05$ & $2.35 \mathrm{E}-03$ \\
\hline \hline
\end{tabular}

Notes: Unadjusted $p$ values and $p$ values adjusted for multiple comparisons using the false discovery rate (FDR) are provided.

For 18,042 of these attachment-associated VMPs the same SNP emerged from the additive (Model 2) and interaction model (Model 3). These nested models permitted a direct comparison of adjusted $R^{2}$ across models. We observed that the interaction $(\mathrm{G} \times \mathrm{E})$ model explained the largest proportion of variance (highest adjusted $R^{2}$ ) in DNA methylation for $58.9 \%$ of attachment-associated VMPs (see Figure 4). In total, $76.4 \%$ of these attachment-associated VMPs benefited from the inclusion of a measure of child genetic variation (Figure 4). We performed a parallel analysis and used AIC to index model fit for prediction models that considered different SNPs across additive and interaction models (i.e., nonnested models) in the prediction of DNA methylation at all attachment-associated VMPs $(n=30,965)$. These analyses revealed somewhat similar results; model fit for approximately half (48.8\%) of all attachment-associated VMPs was improved (i.e., had a lower AIC) when a measure of child genetic variation was considered.

\section{Supplementary analyses}

Infant attachment and moderation of prenatal adversity effects on child outcomes. Measures of prenatal adversity described previously (Silveira et al., 2017) and child outcomes were available on a subset of this sample. Linear regression models revealed that prenatal adversity predicted BRS $(B=$ $-0.934, p=.018$ ) scores from the BSID at 36 months independent of infant attachment and all covariates. Prenatal adversity was associated with both infant MDI $(p=.079)$ and PDI scores $(p=.10)$ at trend level. We observed a significant interaction between prenatal adversity and attachment security to predict the BRS score, $F(2,153)=5.82, p=$ .004 , with an effect of prenatal adversity on infant BRS in the disorganized group only $(B=-3.14, p<.001)$. A similar pattern was observed for MDI scores but did not reach statistical significance, $F(2,151)=2.39, p=.095$ (see Figure 5). Prenatal adversity did not interact with infant attachment to predict infant PDI $(p>.1)$.
Prenatal adversity predicted child total SDQ score $(B=$ $0.71, p=.028$ ) independent of all covariates considered in our SDQ model, including measures of infant attachment and maternal trait anxiety (see Methods). However, prenatal adversity did not interact with infant attachment to predict child total SDQ scores. (See Supplemental Table S.2 for all prenatal adversity linear regression results).

Sex-specific effects of infant attachment on DNA methylation of attachment-associated VMPs. We carried out exploratory analyses to examine potential sex differences in the association between infant attachment and variation in DNA methylation. Analyses stratified by biological sex of our PCA of VMPs revealed a significant association between PC2 and infant attachment in females but not in males (Figure 2). Similar results were observed from our analyses of infant attachment and DNA methylation at individual VMPs. Differences in DNA methylation between secure and disorganized classifications were most pronounced in females but not in males (see Figure 3).

\section{Discussion}

We describe the association between infant attachment at 36 months of age and DNA methylome variation in childhood. To our knowledge this is the first and largest assessment of infant attachment and variation in DNA methylation carried out to date. These findings contribute to a growing literature describing the biological embedding of early experience and suggest a persisting influence of infant attachment on variation in DNA methylation. Our study also provides the first step toward characterizing a molecular signature of infant attachment, which may inform early interventions that seek to promote attachment security.

Our PCA of VMPs showed that infant attachment associates with a significant portion of the variance across the DNA methylome. These data extend those of Moore et al. (2017), 


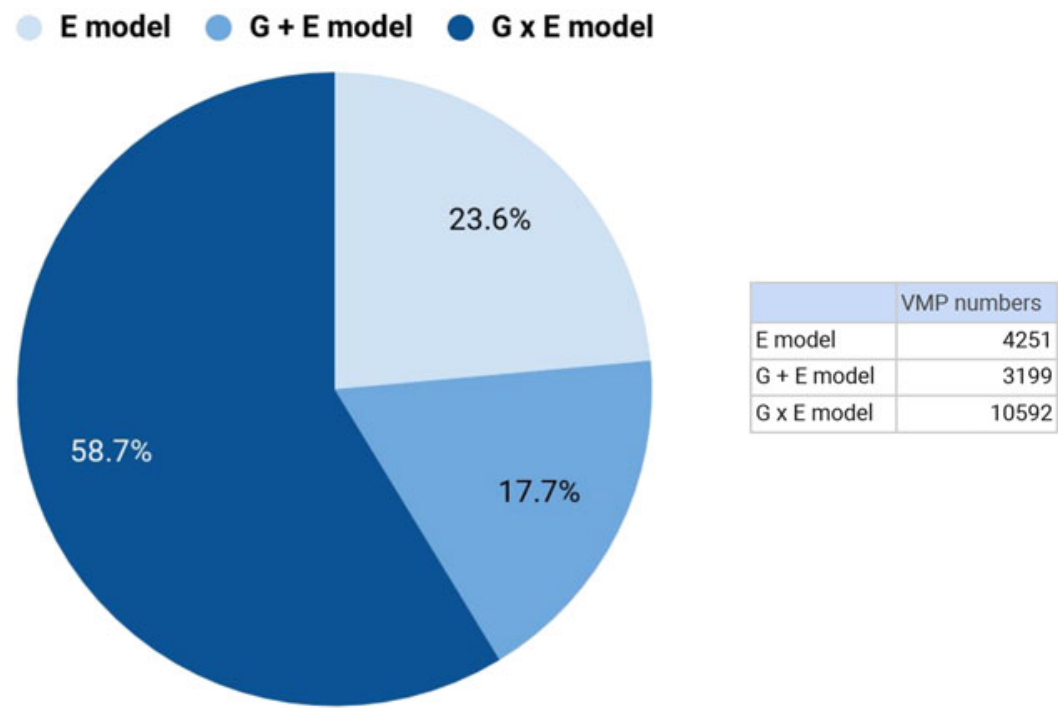

Figure 4. Genetic variation contributes to DNA methylation of attachment-associated variably methylated probes (VMPs). DNA methylation at VMPs were described using linear models that included infant attachment as the environmental predictor (E Model: light blue), the additive effects of infant attachment and a single nucleotide polymorphism (SNP) within 10kb from a VMP (G + E Model: blue), and an interaction model $(\mathrm{G} \times \mathrm{E}$ Model: dark blue) that included infant attachment, a SNP within 10kb from a VMP, and the interaction term between this SNP and infant attachment style. The proportion of variance explained (adjusted $R^{2}$ ) was used to compare models. Percent values on chart denote the number of VMPs that are best explained (highest adjusted $R^{2}$ ) by a specific model, and corresponding numbers of VMPs are provided (see insert). All models were adjusted for buccal cell proportions, population stratification, child age and biological sex, maternal education, and anxiety. kb, kilobase.

and suggest normal variations in the quality of the early caregiving environment may influence variation across the DNA methylome.

Across both our pathway and process enrichment analyses, we observed enrichment for genes related to cell adhesion/cell migration, such as the Ephrin signaling pathway. Ephrins, which bind tyrosine kinase Eph receptors, are critically involved in neuronal interaction, cell migration, and cell differentiation. This is the first report in humans documenting an association of the early care environment and DNA methylation of Ephrin family members; however, our findings draw support from a number of preclinical models. For example, Provençal et al. (2012) report differential DNA methylation of Ephrin family members (ENFB2/ENFA5) in T cells and prefrontal cortex samples from nonhuman primates exposed to their peer-rearing model of early adversity (Provençal et al., 2012). Similarly, female Ephrin knock-out mice (Ephrin-A5 ${ }^{-/-}$) exhibit reduced levels of maternal care toward their offspring (Sheleg et al., 2017). Together with our own data, these findings serve to highlight Ephrin signaling as a novel pathway both sensitive to the effects of the early care environment, and potentially, for promoting caregiving behavior.

We also observed significant enrichment for POMC processing within attachment-associated VMPs. However, we note that this enrichment derives in part from the large number of protein products, which arise from the cleavage of POMC (Pritchard \& White, 2007; Wu et al., 2014). The methylation of the Pomc promoter is influenced by variation in maternal care (Wu et al., 2014), and POMC is centrally involved in glucocorticoid signaling. We also observed differential methylation for a number of VMPs within the glucocorticoid receptor $\mathrm{NR} 3 \mathrm{Cl}$ and glucocorticoid-sensitive targets, including $F K B P 5$ and $S G K 1$, across attachment groups. $S G K 1$ gene expression is increased in blood samples from depressed individuals and also within the hippocampus of prenatally stressed rats (Anacker et al., 2013). Klengel et al. (2013) report altered FKBP5 methylation and glucocorticoid sensitivity following exposure to childhood trauma that covaries with hippocampal volume as well as with clinical symptoms and treatment outcomes in posttraumatic stress disorder (Yehuda et al., 2013).

We also found that infant attachment was associated with variation in DNA methylation at multiple sites within ESRI, which encodes estrogen receptor alpha (ER $\alpha)$. Unfortunately, we were unable to quantify the effects of infant attachment and associated differential methylation of ESRI on its gene expression. Nevertheless, the variation in ESRI methylation as a function of attachment is consistent with studies showing that the frequency of pup licking/grooming in the rat predicts DNA methylation of an Esrl promoter and Esrl expression in the hypothalamus and amygdala (Champagne \& Meaney, 2006; Pena et al., 2013). Binding of ER $\alpha$ to its consensus binding site can influence DNA methylation of target genes (Guintivano, Arad, Gould, Payne, \& Kaminsky, 2013; Kangaspeska et al., 2008; Metivier et al., 2008) consistent with transcription factor-mediated remodeling of the DNA methylome (Stadler et al., 2011; Weaver et al., 2007).

The association between infant attachment and methylation of ESRI is of interest considering the known association 

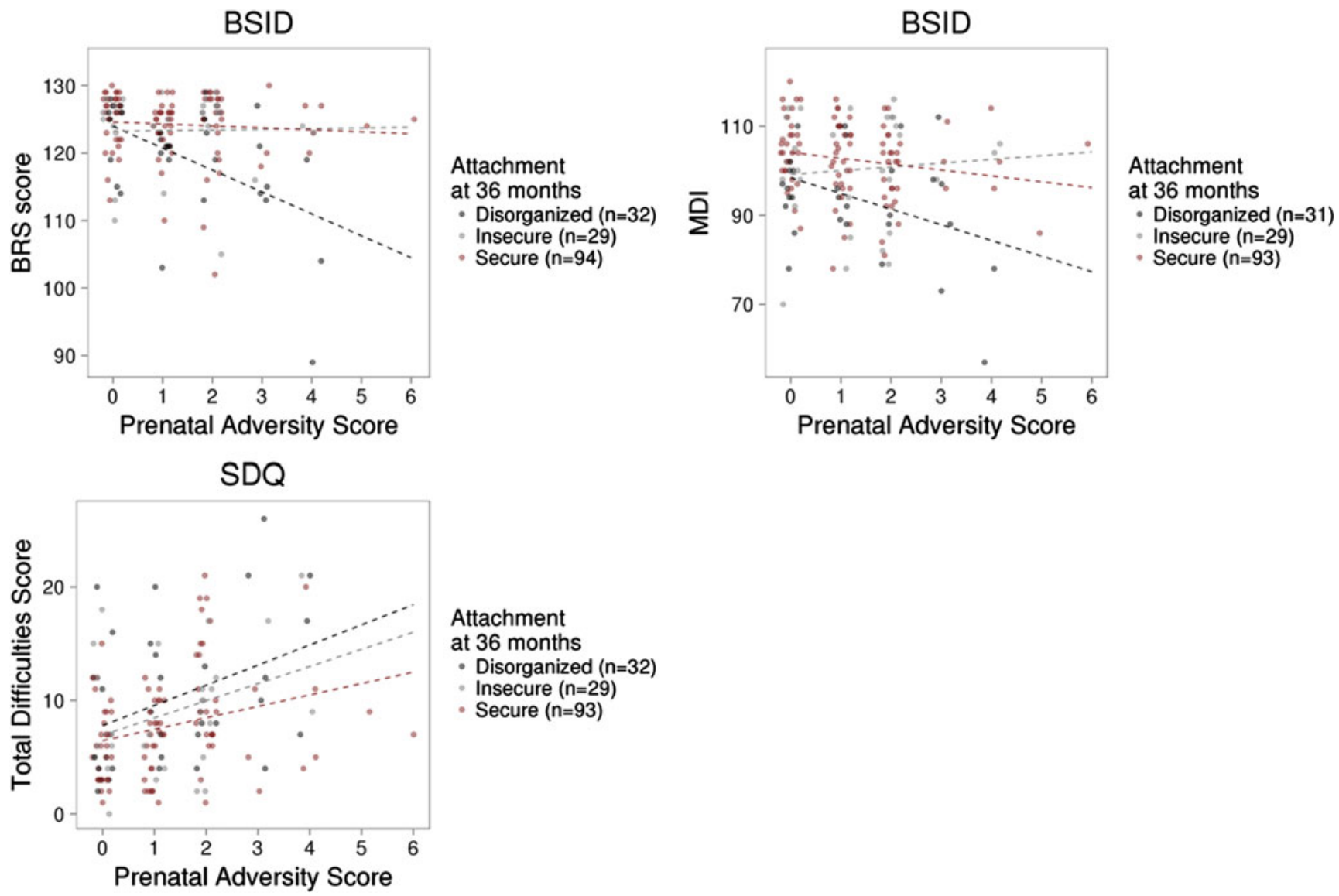

Figure 5. Prenatal adversity, infant attachment, and child outcome. (a) Prenatal adversity interacted with infant attachment to predict the Behavior Rating Scale score of the Bayley Scale of Infant Development (BSID) at 36 months. (b) The interaction between prenatal adversity and infant attachment did not significantly predict the Mental Development Index of the BSID, or (c) total difficulties from the Strengths and Difficulties Questionnaires in middle childhood (mean age $=6.99, S D=1.33$ years).

between the early life experience and the timing of female sexual maturation. The quality of parent-child relations in humans (Ellis \& Essex, 2007; Ellis, Shirtcliff, Boyce, Deardorff, \& Essex, 2011), including attachment insecurity (Belsky \& de Haan, 2011), associate with the timing of female sexual maturation, consistent with life-history theories of early programming of human reproductive strategy under conditions of adversity (Chisholm, 1996). While the precise mechanism linking early family life to the timing of sexual maturation is unknown, there is evidence from Gene $\times$ Environment studies showing that the influence of early family life on the timing of menarche is moderated by ESRI variants (Hartman, Widaman, \& Belsky, 2015; Manuck, Craig, Flory, Halder, \& Ferrell, 2011). It will be of interest to determine if attachment-associated differences in ESRI DNA methylation covary with pubertal timing in females. Likewise, it will be important to determine if an altered rate of female sexual maturation contributes to the marked sex differences we observe in the association between infant attachment and variation in DNA methylation across groups.

Our findings highlight the genome as an important source of variation in DNA methylation of attachment-associated
VMPs, consistent with a large literature on genetic effects on DNA methylation (Hannon et al., 2016; Jaffe et al., 2016; Ng et al., 2017). Models that considered child genetic variation provided the best fit (adjusted $R^{2}$ or AIC) for approximately half of the attachment-associated VMPs. These findings are consistent with those of Teh et al. (2014), who report that the majority of variably methylated regions identified in umbilical cord samples from Singaporean neonates were best explained by gene-environment interactions. Such findings further highlight the need to consider genetic variation when seeking to characterize the biological embedding of early life experience.

In line with previous studies, we found that infant attachment predicted infant cognitive development (Bergman et al., 2010) but also predicted child behavior during this mildly stressful novel stimulus (i.e., the BSID). The association between infant attachment and both MDI and BRS scores represented medium to large effects. Consistent with Bergman et al., we also observed an interaction between a measure of prenatal adversity and infant attachment style to predict BSID scores. However, we note that unlike Bergman et al., our results were restricted to the BRS. It is possible that dif- 
ferences in the age of assessment (17 months vs. 36 months) and our use of a three-group attachment classification system contributed to differences across our studies. However, we do note that the interaction between prenatal adversity and infant attachment is directionally consistent with the previous report (Bergman et al., 2010). As such, our data provide further evidence that attachment security may buffer the effects of prenatal adversity on measures of child outcome (Bergman et al., 2010), which may be of relevance for later psychopathology (McGoron et al., 2012).

We did not observe a significant association between infant attachment and child total mental health symptoms. Our data highlight the importance of adjusting for maternal mood when considering measures of child outcome based on maternal report. Likewise, we did not observe an interaction between prenatal adversity and infant attachment to predict child SDQ. It is possible that our choice of measure (SDQ) contributed to this null finding. In their meta-analysis Fearon et al. (2010) found a stronger association between infant attachment and child externalizing symptoms when assessed through observational methods rather than maternal report.

There are important limitations to this study. First, although this is the largest pediatric study of infant attachment and DNA methylation carried out to date, none of the individual VMPs associated with attachment were significant following adjustment for genome-wide correction. This is not surprising in light of the relatively small effect sizes observed between psychosocial adversity and variation in DNA methylation. Few studies in the field of biological psychiatry report changes in DNA methylation greater than $10 \%$, despite functional effects of such changes on gene expression (Mehta et al., 2013). Our analysis was intended to determine whether infant attachment at 36 months of age was a significant source of interindividual variation in genome-wide DNA methylation. We also

\section{References}

Anacker, C., Cattaneo, A., Musaelyan, K., Zunszain, P. A., Horowitz, M., Molteni, R., . . . Pariante, C. M. (2013). Role for the kinase SGK1 in stress, depression, and glucocorticoid effects on hippocampal neurogenesis. Proceedings of the National Academy of Sciences, 110, 8708-8713. doi: 10.1073/pnas.1300886110

Aryee, M. J., Jaffe, A. E., Corrada-Bravo, H., Ladd-Acosta, C., Feinberg, A. P., Hansen, K. D., \& Irizarry, R. A. (2014). Minfi: A flexible and comprehensive bioconductor package for the analysis of Infinium DNA methylation microarrays. Bioinformatics, 30, 1363-1369. doi:10.1093/ bioinformatics/btu049

Bagot, R. C., Zhang, T. Y., Wen, X., Nguyen, T. T., Nguyen, H. B., Diorio, J., ... Meaney, M. J. (2012). Variations in postnatal maternal care and the epigenetic regulation of metabotropic glutamate receptor 1 expression and hippocampal function in the rat. Proceedings of the National Academy of Sciences, 109(Suppl. 2), 17200-17207. doi:10.1073/pnas.1204599109

Bayley, N. (1993). Bayley Scales of Infant Development (2nd ed.). San Antonio, TX: Psychological Corporation.

Belsky, J., \& de Haan, M. (2011). Annual Research Review: Parenting and children's brain development: The end of the beginning. Journal of Child Psychology and Psychiatry, 52, 409-428. doi:10.1111/j.14697610.2010.02281.x

Belsky, J., Pluess, M., \& Widaman, K. F. (2013). Confirmatory and competitive evaluation of alternative gene-environment interaction hypotheses. Journal of Child Psychology and Psychiatry, 54, 1135-1143. doi:10.1111/jcpp.12075 attempted to limit false-positive findings by including only those probes that showed the interindividual differences (i.e., VMPs). Likewise, due to our use of a three-group classification for infant attachment, our secondary analyses, which considered interactions with prenatal adversity and biological sex, are likely underpowered. As such, these data should be considered preliminary until replicated in an independent sample.

Second, the correspondence between buccal and neuronal methylation profiles is largely unknown. However, it is possible that regions of the genome that are sensitive to steroid hormones, which readily pass the blood-brain barrier, may produce coordinated modifications of DNA methylation across multiple tissues. The increasing availability of publicly available data sets and online tools (Edgar, Jones, Meaney, Turecki, \& Kobor, 2017), which examine the concordance of DNA methylation across peripheral and central tissues, will facilitate the interpretation of findings from studies that use surrogate tissues for brain-based phenotypes.

In summary, our data show that the early care environment covaries with variation in genome-wide DNA methylation in middle childhood. The study of the DNA methylome provides a direct measure of the potential impact of the social environment at the level of the individual child and suggests a persisting influence of infant attachment on the DNA methylome. A deeper understanding of the molecular architecture of infant attachment will help monitor the efficacy of attachment-based therapeutic interventions, which seek to mitigate the lasting effects of early adversity on child development.

\section{Supplementary Material}

To view the supplementary material for this article, please visit https://doi.org/10.1017/S0954579418000627.

Belsky, J., \& van IJzendoorn, M. H. (2017). Genetic differential susceptibility to the effects of parenting. Current Opinion in Psychology, 15, 125 130. doi:10.1016/j.copsyc.2017.02.021

Bergman, K., Sarkar, P., Glover, V., \& O’Connor, T. G. (2010). Maternal prenatal cortisol and infant cognitive development: Moderation by infantmother attachment. Biological Psychiatry, 67, 1026-1032. doi:10.1016/ j.biopsych.2010.01.002

Berko, E. R., Suzuki, M., Beren, F., Lemetre, C., Alaimo, C. M., Calder, R. B., . . . Greally, J. M. (2014). Mosaic epigenetic dysregulation of ectodermal cells in autism spectrum disorder. PLOS Genetics, 10, e1004402. doi:10.1371/journal.pgen.1004402PGENETICS-D-13-02792

Bibikova, M., Barnes, B., Tsan, C., Ho, V., Klotzle, B., Le, J. M., . . . Shen, R. (2011). High density DNA methylation array with single CpG site resolution. Genomics, 98, 288-295. doi:10.1016/j.ygeno.2011. 07.007

Champagne, F. A., \& Meaney, M. J. (2006). Stress during gestation alters postpartum maternal care and the development of the offspring in a rodent model. Biological Psychiatry, 59, 1227-1235. doi:10.1016/j.biopsych.2005.10.016

Chen, Y. A., Lemire, M., Choufani, S., Butcher, D. T., Grafodatskaya, D., Zanke, B. W., . . . Weksberg, R. (2013). Discovery of cross-reactive probes and polymorphic CpGs in the Illumina Infinium HumanMethylation450 microarray. Epigenetics, 8, 203-209. doi:10.4161/epi.23470

Chisholm, J. S. (1996). The evolutionary ecology of attachment organization. Human Nature, 7, 1-37. doi:10.1007/BF02733488 
Edgar, R. D., Jones, M. J., Meaney, M. J., Turecki, G., \& Kobor, M. S. (2017). BECon: A tool for interpreting DNA methylation findings from blood in the context of brain. Translational Psychiatry, 7, e1187. doi:10.1038/tp.2017.171

Ellis, B. J., \& Essex, M. J. (2007). Family environments, adrenarche, and sexual maturation: A longitudinal test of a life history model. Child Development, 78, 1799-1817. doi:10.1111/j.1467-8624.2007.01092.x

Ellis, B. J., Shirtcliff, E. A., Boyce, W. T., Deardorff, J., \& Essex, M. J. (2011). Quality of early family relationships and the timing and tempo of puberty: Effects depend on biological sensitivity to context. Development and Psychopathology, 23, 85-99. doi:10.1017/ S0954579410000660

Fearon, R. P., Bakermans-Kranenburg, M. J., van IJzendoorn, M. H., Lapsley, A. M., \& Roisman, G. I. (2010). The significance of insecure attachment and disorganization in the development of children's externalizing behavior: A meta-analytic study. Child Development, 81, 435-456. doi:10.1111/j.1467-8624.2009.01405.x

Forest, M., O'Donnell, K. J., Voisin, G., Gaudreau, H., MacIsaac, J. L., McEwen, L. M., . . . Greenwood, C. M. T. (2018). Agreement in DNA methylation levels from the Illumina $450 \mathrm{~K}$ array across batches, tissues, and time. Epigenetics, 13, 19-32.

Fortin, J. P., Labbe, A., Lemire, M., Zanke, B. W., Hudson, T. J., Fertig, E. J., ... Hansen, K. D. (2014). Functional normalization of 450k methylation array data improves replication in large cancer studies. Genome Biology, 15, 503. doi:10.1186/s13059-014-0503-2

Goodman, R., Ford, T., Simmons, H., Gatward, R., \& Meltzer, H. (2000). Using the Strengths and Difficulties Questionnaire (SDQ) to screen for child psychiatric disorders in a community sample. British Journal of Psychiatry, 177, 534-539.

Goodman, R., Meltzer, H., \& Bailey, V. (1998). The Strengths and Difficulties Questionnaire: A pilot study on the validity of the self-report version. European Child \& Adolescent Psychiatry, 7, 125-130. doi:10.1007/ s007870050057

Goodman, R., Renfrew, D., \& Mullick, M. (2000). Predicting type of psychiatric disorder from Strengths and Difficulties Questionnaire (SDQ) scores in child mental health clinics in London and Dhaka. European Child \& Adolescent Psychiatry, 9, 129-134. doi:10.1007/ s007870050008

Groh, A. M., Fearon, R. P., Bakermans-Kranenburg, M. J., van IJzendoorn, M. H., Steele, R. D., \& Roisman, G. I. (2014). The significance of attachment security for children's social competence with peers: A meta-analytic study. Attachment \& Human Development, 16, 103-136. doi:10.1080/ 14616734.2014 .883636

Groh, A. M., Roisman, G. I., van Ijzendoorn, M. H., Bakermans-Kranenburg, M. J., \& Fearon, R. P. (2012). The significance of insecure and disorganized attachment for children's internalizing symptoms: A meta-analytic study. Child Development, 83, 591-610. doi:10.1111/j.1467-8624.2011. 01711.x

Guintivano, J., Arad, M., Gould, T. D., Payne, J. L., \& Kaminsky, Z. A. (2013). Antenatal prediction of postpartum depression with blood DNA methylation biomarkers. Molecular Psychiatry, 19, 560-567. doi: $10.1038 / \mathrm{mp} .2013 .62$

Hannon, E., Spiers, H., Viana, J., Pidsley, R., Burrage, J., Murphy, T. M., . . . Mill, J. (2016). Methylation QTLs in the developing brain and their enrichment in schizophrenia risk loci. Nature Neuroscience, 19, 48-54. doi:10.1038/nn.4182

Hartman, S., Widaman, K. F., \& Belsky, J. (2015). Genetic moderation of effects of maternal sensitivity on girl's age of menarche: Replication of the Manuck et al. study. Development and Psychopathology, 27, 747-756. doi:10.1017/S0954579414000856

Jaffe, A. E., Gao, Y., Deep-Soboslay, A., Tao, R., Hyde, T. M., Weinberger, D. R., \& Kleinman, J. E. (2016). Mapping DNA methylation across development, genotype and schizophrenia in the human frontal cortex. $\mathrm{Na}$ ture Neuroscience, 19, 40-47. doi:10.1038/nn.4181

Johnson, W. E., Li, C., \& Rabinovic, A. (2007). Adjusting batch effects in microarray expression data using empirical Bayes methods. Biostatistics, 8, 118-127. doi:10.1093/biostatistics/kxj037

Kangaspeska, S., Stride, B., Metivier, R., Polycarpou-Schwarz, M., Ibberson, D., Carmouche, R. P., . . . Reid, G. (2008). Transient cyclical methylation of promoter DNA. Nature, 452, 112-115.

Klengel, T., Mehta, D., Anacker, C., Rex-Haffner, M., Pruessner, J. C., Pariante, C. M., . . Binder, E. B. (2013). Allele-specific FKBP5 DNA demethylation mediates gene-childhood trauma interactions. Nature Neuroscience, 16, 33-41.
Lam, L. L., Emberly, E., Fraser, H. B., Neumann, S. M., Chen, E., Miller, G. E., \& Kobor, M. S. (2012). Factors underlying variable DNA methylation in a human community cohort. Proceedings of the National Academy of Sciences, 109(Suppl. 2), 17253-17260. doi:10.1073/ pnas. 1121249109

Lehne, B., Drong, A. W., Loh, M., Zhang, W., Scott, W. R., Tan, S. T., . . Chambers, J. C. (2015). A coherent approach for analysis of the Illumina HumanMethylation450 BeadChip improves data quality and performance in epigenome-wide association studies. Genome Biology, 16, 37. doi:10.1186/s13059-015-0600-x

Lowe, R., Gemma, C., Beyan, H., Hawa, M. I., Bazeos, A., Leslie, R. D., . . Ramagopalan, S. V. (2013). Buccals are likely to be a more informative surrogate tissue than blood for epigenome-wide association studies. Epigenetics, 8. doi: 24362

Manuck, S. B., Craig, A. E., Flory, J. D., Halder, I., \& Ferrell, R. E. (2011). Reported early family environment covaries with menarcheal age as a function of polymorphic variation in estrogen receptor-alpha. Development and Psychopathology, 23, 69-83. doi:10.1017/S0954579410000659

Marr, A. K., MacIsaac, J. L., Jiang, R., Airo, A. M., Kobor, M. S., \& McMaster, W. R. (2014). Leishmania donovani infection causes distinct epigenetic DNA methylation changes in host macrophages. PLOS Pathogens, 10, e1004419. doi:10.1371/journal.ppat.1004419

Maunakea, A. K., Chepelev, I., Cui, K., \& Zhao, K. (2013). Intragenic DNA methylation modulates alternative splicing by recruiting MeCP2 to promote exon recognition. Cell Research, 23, 1256-1269. doi:10.1038/ cr.2013.110

Maunakea, A. K., Nagarajan, R. P., Bilenky, M., Ballinger, T. J., D’Souza, C., Fouse, S. D., . . C Costello, J. F. (2010). Conserved role of intragenic DNA methylation in regulating alternative promoters. Nature, 466 , 253-257.

McGoron, L., Gleason, M. M., Smyke, A. T., Drury, S. S., Nelson., C. A., III, Gregas, M. C., . . Zeanah, C. H. (2012). Recovering from early deprivation: Attachment mediates effects of caregiving on psychopathology. Journal of the American Academy of Child \& Adolescent Psychiatry, 51, 683-693. doi:10.1016/j.jaac.2012.05.004

McLaughlin, K. A., Sheridan, M. A., Winter, W., Fox, N. A., Zeanah, C. H. \& Nelson, C. A. (2014). Widespread reductions in cortical thickness following severe early-life deprivation: A neurodevelopmental pathway to attention-deficit/hyperactivity disorder. Biological Psychiatry, 76, 629638. doi:10.1016/j.biopsych.2013.08.016

Meaney, M. J., \& Ferguson-Smith, A. C. (2010). Epigenetic regulation of the neural transcriptome: The meaning of the marks. Nature Neuroscience, 13, 1313-1318.

Mehta, D., Klengel, T., Conneely, K. N., Smith, A. K., Altmann, A., Pace, T. W., . . . Binder, E. B. (2013). Childhood maltreatment is associated with distinct genomic and epigenetic profiles in posttraumatic stress disorder. Proceedings of the National Academy of Sciences, 110, 8302-8307. doi:10.1073/pnas.1217750110

Metivier, R., Gallais, R., Tiffoche, C., Le Peron, C., Jurkowska, R. Z., Carmouche, R. P., . . Salbert, G. (2008). Cyclical DNA methylation of a transcriptionally active promoter. Nature, 452, 45-50.

Moore, S. R., McEwen, L. M., Quirt, J., Morin, A., Mah, S. M., Barr, R. G., ... Kobor, M. S. (2017). Epigenetic correlates of neonatal contact in humans. Development and Psychopathology, 29, 1517-1538. doi:10.1017/ S0954579417001213

Moss, E., Bureau, J. F., Cyr, C., Mongeau, C., \& St.-Laurent, D. (2004). Correlates of attachment at age 3: Construct validity of the preschool attachment classification system. Developmental Psychology, 40, 323-334. doi:10.1037/0012-1649.40.3.323

Moss, E., Cyr, C., Bureau, J. F., Tarabulsy, G. M., \& Dubois-Comtois, K. (2005). Stability of attachment during the preschool period. Developmental Psychology, 41, 773-783. doi:10.1037/00121649.41.5.773

Murgatroyd, C., Patchev, A. V., Wu, Y., Micale, V., Bockmuhl, Y., Fischer, D., ... Spengler, D. (2009). Dynamic DNA methylation programs persistent adverse effects of early-life stress. Nature Neuroscience, 12, 15591566. doi: $10.1038 / \mathrm{nn} .2436$

Nanni, V., Uher, R., \& Danese, A. (2012). Childhood maltreatment predicts unfavorable course of illness and treatment outcome in depression: A meta-analysis. American Journal of Psychiatry, 169, 141-151.

Nelson, C. A., Zeanah, C. H., Fox, N. A., Marshall, P. J., Smyke, A. T., \& Guthrie, D. (2007). Cognitive recovery in socially deprived young children: The Bucharest Early Intervention Project. Science, 318, 1937-1940. doi:10.1126/science.1143921 
Ng, B., White, C. C., Klein, H. U., Sieberts, S. K., McCabe, C., Patrick, E., .. De Jager, P. L. (2017). An XQTL map integrates the genetic architecture of the human brain's transcriptome and epigenome. Nature Neuroscience, 20, 1418-1426. doi:10.1038/nn.4632

O'Donnell, K. A., Gaudreau, H., Colalillo, S., Steiner, M., Atkinson, L., Moss, E., . . . MARVAN Research Team. (2014). The maternal adversity, vulnerability and neurodevelopment project: Theory and methodology. Canadian Journal of Psychiatry, 59, 497-508. doi:10.1177/ 070674371405900906

O’Donnell, K. J., Chen, L., MacIsaac, J. L., McEwen, L. M., Nguyen, T., Beckmann, K., . . . Meaney, M. J. (2018). DNA methylome variation in a perinatal nurse-visitation program that reduces child maltreatment: A 27-year follow-up. Translational Psychiatry, 8, 15. doi:10.1038/ s41398-017-0063-9

O’Donnell, K. J., Glover, V., Barker, E. D., \& O'Connor, T. G. (2014). The persisting effect of maternal mood in pregnancy on childhood psychopathology. Development and Psychopathology, 26, 393-403. doi:10.1017/ S0954579414000029

O’Donnell, K. J., Glover, V., Holbrook, J. D., \& O'Connor, T. G. (2014). Maternal prenatal anxiety and child brain-derived neurotrophic factor (BDNF) genotype: Effects on internalizing symptoms from 4 to 15 years of age. Development and Psychopathology, 26(4, Pt 2), 1255-1266. doi:10.1017/S095457941400100X

O’Donnell, K. J., Glover, V., Lahti, J., Lahti, M., Edgar, R. D., Raikkonen, K., \& O'Connor, T. G. (2017). Maternal prenatal anxiety and child COMT genotype predict working memory and symptoms of ADHD. PLOS ONE, 12, e0177506. doi:10.1371/journal.pone.0177506

O'Donnell, K. J., \& Meaney, M. J. (2016). Fetal origins of mental health: The developmental origins of health and disease hypothesis. American Journal of Psychiatry. Advance online publication. doi:10.1176/appi.ajp.2016.16020138

Pan, H., Chen, L., Dogra, S., Ling Teh, A., Tan, J. H., Lim, Y. I., . . . Holbrook, J. D. (2012). Measuring the methylome in clinical samples: Improved processing of the Infinium Human Methylation450 BeadChip Array. Epigenetics, 7, 1173-1187.

Papavassiliou, P., York, T. P., Gursoy, N., Hill, G., Nicely, L. V., Sundaram, U., . . Jackson-Cook, C. (2009). The phenotype of persons having mosaicism for trisomy 21/Down syndrome reflects the percentage of trisomic cells present in different tissues. American Journal of Medical Genetics Part A, 149A, 573-583. doi:10.1002/ajmg.a.32729

Pawlby, S., Hay, D. F., Sharp, D., Waters, C. S., \& O'Keane, V. (2009). Antenatal depression predicts depression in adolescent offspring: Prospective longitudinal community-based study. Journal of Affective Disorders, 113, 236-243. doi:10.1016/j.jad.2008.05.018

Pena, C. J., Neugut, Y. D., \& Champagne, F. A. (2013). Developmental timing of the effects of maternal care on gene expression and epigenetic regulation of hormone receptor levels in female rats. Endocrinology, 154, 4340-4351. doi:10.1210/en.2013-1595

Price, A. L., Patterson, N. J., Plenge, R. M., Weinblatt, M. E., Shadick, N. A., $\&$ Reich, D. (2006). Principal components analysis corrects for stratification in genome-wide association studies. Nature Genetics, 38, 904-909. doi: $10.1038 / n g 1847$

Price, M. E., Cotton, A. M., Lam, L. L., Farre, P., Emberly, E., Brown, C. J., . . Kobor, M. S. (2013). Additional annotation enhances potential for biologically-relevant analysis of the Illumina Infinium HumanMethylation450 BeadChip array. Epigenetics Chromatin, 6, 4. doi:10.1186/ 1756-8935-6-4

Pritchard, L. E., \& White, A. (2007). Neuropeptide processing and its impact on melanocortin pathways. Endocrinology, 148, 4201-4207. doi:10.1210/en.2006-1686

Provençal, N., Suderman, M. J., Guillemin, C., Massart, R., Ruggiero, A., Wang, D., . . Szyf, M. (2012). The signature of maternal rearing in the methylome in rhesus macaque prefrontal cortex and T cells. Journal of Neuroscience, 32, 15626-15642. doi:10.1523/jneurosci.1470-12.2012

$R$ Core Team. (2014). $R$ : A language and environment for statistical computing. Vienna, Austria: Foundation for Statistical Computing.

Roth, T. L., Lubin, F. D., Funk, A. J., \& Sweatt, J. D. (2009). Lasting epigenetic influence of early-life adversity on the BDNF gene. Biological Psychiatry, 65, 760-769. doi:10.1016/j.biopsych.2008.11.028

Rutter, M., Kumsta, R., Schlotz, W., \& Sonuga-Barke, E. (2012). Longitudinal studies using a "natural experiment" design: The case of adoptees from Romanian institutions. Journal of the American Academy of Child \& Adolescent Psychiatry, 51, 762-770. doi:10.1016/j.jaac.2012.05.011
Scholtens, S., Rydell, A.-M., Bohlin, G., \& Thorell, L. (2014). ADHD symptoms and attachment representations: Considering the role of conduct problems, cognitive deficits and narrative responses in non-attachmentrelated story stems. Journal of Abnormal Child Psychology, 42, 10331042. doi:10.1007/s10802-014-9854-0

Sheleg, M., Yu, Q., Go, C., Wagner, G. C., Kusnecov, A. W., \& Zhou, R. (2017). Decreased maternal behavior and anxiety in ephrin-A5(-/-) mice. Genes, Brain and Behavior, 16, 271-284. doi:10.1111/gbb.12319

Silveira, P. P., Pokhvisneva, I., Parent, C., Cai, S., Rema, A. S. S., Broekman, B. F. P., . . Meaney, M. J. (2017). Cumulative prenatal exposure to adversity reveals associations with a broad range of neurodevelopmental outcomes that are moderated by a novel, biologically informed polygenetic score based on the serotonin transporter solute carrier family C6, member 4 (SLC6A4) gene expression. Development and Psychopathology, 29, 1601-1617. doi:10.1017/S0954579417001262

Smith, A. K., Kilaru, V., Klengel, T., Mercer, K. B., Bradley, B., Conneely, K. N., . . . Binder, E. B. (2015). DNA extracted from saliva for methylation studies of psychiatric traits: Evidence tissue specificity and relatedness to brain. American Journal of Medical Genetics Part B: Neuropsychiatric Genetics, 168B, 36-44. doi:10.1002/ajmg.b.32278

Sonuga-Barke, E. J. S., Kennedy, M., Kumsta, R., Knights, N., Golm, D., Rutter, M., . . . Kreppner, J. (2017). Child-to-adult neurodevelopmental and mental health trajectories after early life deprivation: The young adult follow-up of the longitudinal English and Romanian Adoptees study. Lancet, 389, 1539-1548. doi:10.1016/S0140-6736(17)30045-4

Spatz Widom, C., DuMont, K., \& Czaja, S. J. (2007). A prospective investigation of major depressive disorder and comorbidity in abused and neglected children grown up. Archives of General Psychiatry, 64, $49-56$.

Spielberger, C. D., Gorusch, R. L., \& Lushene, R. E. (1970). STAI manual for the State-trait Anxiety Inventory. Pao Alto, CA: Consulting Psychologists Press.

Stadler, M. B., Murr, R., Burger, L., Ivanek, R., Lienert, F., Scholer, A., . . . Schubeler, D. (2011). DNA-binding factors shape the mouse methylome at distal regulatory regions. Nature, 480, 490-495. doi:10.1038/nature 10716

Stocker, C. M., Masarik, A. S., Widaman, K. F., Reeb, B. T., Boardman, J. D., Smolen, A., . . Conger, K. J. (2017). Parenting and adolescents' psychological adjustment: Longitudinal moderation by adolescents' genetic sensitivity. Development and Psychopathology, 29, 1289-1304. doi:10.1017/S0954579416001310

Suderman, M., McGowan, P. O., Sasaki, A., Huang, T. C. T., Hallett, M. T., Meaney, M. J., . . . Szyf, M. (2012). Conserved epigenetic sensitivity to early life experience in the rat and human hippocampus. Proceedings of the National Academy of Sciences, 109(Suppl. 2), 17266-17272. doi:10.1073/pnas.1121260109

Teh, A. L., Pan, H., Chen, L., Ong, M. L., Dogra, S., Wong, J., . . Holbrook, J. D. (2014). The effect of genotype and in utero environment on inter-individual variation in neonate DNA methylomes. Genome Research, 24, 1064-1074. doi:10.1101/gr.171439.113

Weaver, I. C., D’Alessio, A. C., Brown, S. E., Hellstrom, I. C., Dymov, S., Sharma, S., . . Meaney, M. J. (2007). The transcription factor nerve growth factor-inducible protein a mediates epigenetic programming: Altering epigenetic marks by immediate-early genes. Journal of Neuroscience, 27, 1756-1768. doi:10.1523/JNEUROSCI.4164-06.2007

Weaver, I. C. G., Cervoni, N., Champagne, F. A., D’Alessio, A. C., Sharma, S., Seckl, J. R., . . . Meaney, M. J. (2004). Epigenetic programming by maternal behavior. Nature Neuroscience, 7, 847-854.

Wu, Y., Patchev, A. V., Daniel, G., Almeida, O. F., \& Spengler, D. (2014). Early-life stress reduces DNA methylation of the Pomc gene in male mice. Endocrinology, 155, 1751-1762. doi:10.1210/en.2013-1868

Yehuda, R., Daskalakis, N. P., Desarnaud, F., Makotkine, I., Lehrner, A. L., Koch, E., . . . Bierer, L. M. (2013). Epigenetic biomarkers as predictors and correlates of symptom improvement following psychotherapy in combat veterans with PTSD. Frontiers in Psychiatry, 4, 118. doi: $10.3389 /$ fpsyt.2013.00118

Zhang, T. Y., Hellstrom, I. C., Bagot, R. C., Wen, X., Diorio, J., \& Meaney, M. J. (2010). Maternal care and DNA methylation of a glutamic acid decarboxylase 1 promoter in rat hippocampus. Journal of Neuroscience, 30 , 13130-13137. doi:10.1523/JNEUROSCI.1039-10.2010

Ziller, M. J., Gu, H., Muller, F., Donaghey, J., Tsai, L. T., Kohlbacher, O., . . . Meissner, A. (2013). Charting a dynamic DNA methylation landscape of the human genome. Nature, 500, 477-481. doi:10.1038/nature12433 